\title{
Cómodo y una decisión estratégica: el fin de la expeditio Germanica en $180^{1}$
}

\section{Commodus and a Strategic Decision: the End of the expeditio Germanica in 180}

\author{
Andrés Sáez Geoffroy \\ https://orcid.org/0000-0003-1538-4011 \\ Universidad de La Frontera, Chile \\ andres.saez@ufrontera.cl
}

\begin{abstract}
Resumen: Cómodo ha sido visto como un emperador disoluto que lanzó por el despeñadero los logros del Siglo de Oro de los Antoninos. En el presente artículo intentaremos analizar una de las primeras decisiones que tuvo que tomar el joven emperador: proseguir o terminar las campañas dirigidas por Marco Aurelio. Sostendremos a lo largo de este trabajo que las decisiones estratégicas y militares de Cómodo fueron racionales en relación con el pensamiento militar romano del siglo II, aportando al debate historiográfico una nueva visión sobre dicho gobernante y la toma de decisiones por parte de los emperadores.

Palabras clave: Cómodo, Grand Strategy, Marco Aurelio, Antoninos, Imperio romano
\end{abstract}

AbstRact: Commodus has been considered as a profligate emperor who threw over all the Golden Age achievements during the Antonine dinasty. In this article we will try to analyze one of the first decisions that the young emperor had to make, whether to continue or quit the campaigns commanded by Marcus Aurelius. Throughout this work we shall support the idea that strategic and military decisions of Commodus were rational regarding the Roman military thought of the Second Century, so we will contribute to Historiographical debate with a new vision of Commodus and of how Roman emperors made their decisions.

Keywords: Commodus, Grand Strategy, Marcus Aurelius, Antonines, Roman Empire

RECIBIDO: 15/04/2019 • ACEPTADO: 02/08/2019 • Versión FINAL: 12/09/2019

\footnotetext{
${ }^{1}$ Este artículo se inserta en el proyecto Fondecyt de Iniciación N 11180219 , titulado: "La Pax Antonina: ideología militar, política exterior y gran estrategia del Imperio romano en el siglo de los Antoninos". 


\section{INTRODUCCIÓN}

Cómodo ha sido visto por las fuentes y relatos históricos negativamente, como un emperador cuya obra es digna émula de Calígula, Nerón y Domiciano. En una célebre frase del historiador bitinio Dión Casio el principado de Cómodo trastocó una era de oro por una de óxido. ${ }^{2}$ En nuestra época esta visión ha sido resaltada por obras cinematográficas tales como La caída del Imperio romano (1964), Gladiador (2000) y una serie en Netflix llamada el Imperio romano (2016). A partir de estas cuestiones la imagen histórica de Cómodo se ha prolongado hasta el día de hoy como un arquetipo de mal gobernante, más preocupado por satisfacer su hedonismo que por gobernar.

A nuestro juicio es necesario explicar ciertos hechos históricos de su principado, ya que cabría preguntarse si fue efectivamente un emperador disoluto, cuyas decisiones estuvieron dictadas por la búsqueda de placeres, y si esto también se aplica a las decisiones militares. Comprender su actuación no implica obviar su política antisenatorial. Desde mediados del siglo xx la historiografía se concentró en reconstituir su gobierno dándole una coherencia temporal y un sentido al antiguo relato moral sobre su mandato. ${ }^{3}$ A pesar de esos enormes avances aún quedan cuestiones por estudiar, no exentas de complicaciones por la ausencia de fuentes y por el retrato moral que los relatos de los siglos III y IV nos proporcionan acerca del último emperador Antonino.

Considerando lo anterior, en este artículo nos proponemos analizar a profundidad la primera decisión estratégico-militar que tomó Cómodo, a saber, la realización de una breve campaña en 180 y la firma de un tratado de paz que supuestamente desaprovechó las ventajas militares y geográficas conseguidas por Marco Aurelio, la más importante de ellas era lograr anexar al Imperio romano los territorios al norte del Danubio. Partiendo de la idea de que las narraciones de los sucesos del 180 al 193 están plagadas de incongruencias y exageraciones, tomaremos como base la discusión inacabada sobre la existencia o no de una concepción estratégica compleja para el Imperio romano. ${ }^{4}$

En el desarrollo de este trabajo utilizaremos la metodología propuesta por Alföldy para la historia antigua, sustentada en una nueva lectura de las fuentes del periodo histórico y su correlación con los modelos explicativos del desarrollo de la estrategia imperial. Esta reinterpretación la realizaremos tomando un hecho puntual: la decisión imperial de terminar la campaña

\footnotetext{
2 D.C., 72, 35, 4, ed. 1927.

${ }^{3}$ Hekster 2002, pp. 2-3.

${ }^{4}$ Sáez 2017, pp. 1-25, ofrece una síntesis del debate de los últimos 40 años, porque el artículo no busca centrarse en el debate en sí mismo.
} 
del Danubio para volver a Roma y la relacionaremos con otras fuentes del periodo. Nuestra premisa central será que la paz con los germanos en 180 reflejó una serie de elementos que nos permiten presuponer un pensamiento estratégico romano. La comprensión de la toma de decisiones se ha analizado de dos maneras: una, por un grupo de historiadores que acepta que el Imperio romano tomaba decisiones en ese sentido y otra, por un grupo de historiadores que niega que la estructura política romana haya sido capaz de tomar determinaciones de ese tipo. Por medio de la coyuntura militar del 180 nos adentraremos en el reinado de Cómodo. ${ }^{5}$

\section{CÓMODO Y SU ASCENSO AL PODER: LAS FUENTES Y LA HISTORIOGRAFÍA}

Las fuentes nos presentan en términos generales a Cómodo asumiendo el poder con patrocinio de su padre y la protección de los amigos de él. ${ }^{6}$ Pero el joven emperador de 19 años, según las fuentes, quiso regresar a Roma para disfrutar los placeres de la vida mundana. Sus actitudes terminaron por sepultar los supuestos proyectos de su padre y el eterno deseo romano de conquistar a los germanos. En los hechos, Cómodo decidió volver a Roma en la segunda mitad del 180, encargando a sus legados que lucharan los últimos combates de la guerra germánica, iniciada por su padre, que le llevaron a celebrar en octubre de ese año un triunfo y su cuarta salutación imperial.

Como señala Urbano Espinosa, las fuentes describen a Cómodo como un "gigantesco monstruo cargado de cuantos vicios la mente humana pueda imaginar y carente de la mínima brizna de virtud". ${ }^{7}$ Con aquellas connotaciones la historiografía romana, más cercana al retrato moral del buen o mal gobernante, nos presenta a un emperador cuyas decisiones estuvieron mediadas por la satisfacción de sus instintos por sobre las tareas de un estadista romano. Hay que tener cuidado, por tanto, en cómo reflexionamos e interpretamos las decisiones de Cómodo, ya que fueron vistas en el marco de su locura o bien en comparación con las de su padre, un muy buen emperador para las fuentes romanas. En síntesis, la historiografía reciente ha concluido que las fuentes nos revelan un emperador que representa el estereotipo del mal gobernante más que una figura histórica. ${ }^{8}$

Dión Casio, contemporáneo a los hechos, menciona que Marco Aurelio le dejó a Cómodo guardianes senatoriales para que frenaran sus bajos instintos juveniles e impidieran la seducción de sus disolutos compañeros. ${ }^{9}$ Pero el

\footnotetext{
${ }^{5}$ Wheeler 1993a, pp. 7-41. Valdés 2011, pp. 89-104.

${ }^{6}$ Cf. Crook 1975, p. 3, respecto a los amigos de los emperadores como consejeros.

${ }^{7}$ Espinosa 1984, p. 125.

${ }^{8}$ Garzetti 1974, pp. 532-533.

${ }^{9}$ D.C., 73, 1, 1, ed. 1927.
} 
joven emperador rechazó los consejos de los prohombres del Senado, pudiendo haber derrotado a unos débiles pueblos germanos, pactó con ellos y retornó a Roma. ${ }^{10}$

La visión de Herodiano no difiere en lo esencial de lo declarado por Dión Casio. Según él, el emperador filósofo se esmeró en darle a Cómodo una educación de excelencia, pero el gran miedo del emperador era que su hijo ascendiera al poder siendo aún adolescente, atendiendo a los ejemplos de malos gobernantes jóvenes como Nerón o Domiciano. ${ }^{11}$ Junto a ello Marco Aurelio tenía por "su mayor preocupación la prosecución de la campaña contra Germania". ${ }^{12} \mathrm{Al}$ morir éste, sus amigos se afanaron para guiar los primeros pasos del nuevo gobernante en cumplir los deseos de su progenitor; pero después de conversaciones y diálogos, en los cuales Herodiano pone como vocero a Tiberio Claudio Pompeyano, cuñado del emperador, Cómodo decidió firmar la paz con los germanos y volver a Roma, desestimando todos los consejos de los amigos de su padre. En la Historia Augusta se repite el tópico de la educación, mas Cómodo cedió a las estipulaciones del enemigo y raudamente remisit ad Roma. ${ }^{13}$

Hay un relato algo diferente de la ascensión de Cómodo a la púrpura imperial en los breviarios del siglo iv. Según Eutropio, aquél luchó con éxito contra Germanos feliciter et ipse pugnavit. ${ }^{14}$ Aurelio Víctor dice que fue temerario en la guerra, sobre todo en la llevada con éxito sobre los cuados. ${ }^{15}$ Pero, salvo esto, en el resto de los relatos aparece la mácula de la maldad del último Antonino.

En el siglo XVIII aún encontramos ecos de esa visión. Para Edward Gibbon, una vez muerto Marco Aurelio: "The servile and profligate youths whom Marcus had banished, soon regained their station and influence about the new emperor". ${ }^{16}$ Visiones algo refinadas de aquellas lógicas de enfocar a Cómodo se pueden observar en las biografías de Marco Aurelio: tanto Birley como MacLynn deslizan tímidamente que la peor decisión que pudo haber tomado el emperador filósofo fue haber dejado a su hijo a cargo del Imperio. ${ }^{17}$ Pero esa idea sólo la podemos explicar desde una visión retrospectiva y no desde el momento mismo de los hechos, cuando la opción más lógica fue el nombramiento de Cómodo como César en 175, y su partida inmediata junto a su padre en la expeditio Germanica secunda. ${ }^{18}$

\footnotetext{
${ }^{10}$ D.C., 73, 2, 1, ed. 1927.

${ }^{11}$ Hdn., 1, 3, 1-2, ed. 1985

12 Hdn., 1, 3, 5, ed. 1985, trad. de Torres Esbarranch.

${ }^{13}$ SHA., Comm., 3, 5, ed. 1922, trad. de Picón y Cascón: "se volvió a Roma".

${ }^{14}$ Eutr., 8, 15, ed. 1865, trad. de Falque: "luchó con éxito contra los germanos".

15 Aur. Vict., Caes., 17, 2, ed. 2008.

${ }^{16}$ Gibbon 1830, p. 34.

${ }^{17}$ Birley 1993, pp. 224-225. MacLynn 2011, pp. 487-502.

${ }^{18}$ Hekster 2002, pp. 26-31.
} 
La imagen historiográfica de Cómodo ha ido cambiando desde mediados del siglo xx debido a una nueva comprensión de su época. Fue con la obra de Grosso La lotta politica al tempo di Commodo ${ }^{19}$ que se realizó el primer análisis serio de su mandato, lográndose reconstruir la cronología, hechos y acciones del mismo. Se trata de un trabajo con fuerte contenido narrativo, con base en una gran cantidad de referencias; la preocupación de Grosso no fue generar un marco para comprender las actuaciones de Cómodo, sino reunir antecedentes y fuentes de su periodo para construir un relato más objetivo. ${ }^{20}$ No obstante, aún perviven visiones totalmente negativas de su gobierno. En una obra reciente de una prestigiosa editorial de temas militares se señala que "Este Augusto incapaz se enfrentó a diversos desafíos, no tan graves como los de su padre. [...] no mostrándose interesado en otra lucha que la que se libraba en la arena de los anfiteatros", ${ }^{21}$ presentándonos una figura histórica enjuiciada y condenada.

Fiel a su proposición metodológica de reinterpretar las fuentes, Alföldy fue uno de los pioneros en reestudiar la paz del 180 a partir de un análisis crítico de las narraciones del periodo. ${ }^{22}$ Para el historiador húngaro-alemán la firma de los tratados de paz por Cómodo fue un gran punto de inflexión en la historia romana. ${ }^{23}$ Sostuvo en primer lugar que Marco Aurelio no deseó anexar provincias más allá del Danubio, por eso las campañas y tratados de Cómodo sólo reforzaron las ideas que su padre tenía al momento de su muerte. ${ }^{24}$ Por ello la política exterior del joven emperador presentó más elementos de continuidad que de cambio.

Este trabajo abrió nuevas perspectivas, la última que podemos destacar es la de Hekster. Según este autor el repliegue de Cómodo del Danubio "is hotly discussed", ${ }^{25}$ la retirada bajo el argumento del disfrute de placeres es un argumento simplón para una decisión crucial en la política exterior del Imperio romano. Desde un punto de vista doméstico, Cómodo como emperador joven y recién ascendido no podía permitirse políticamente la pérdida de prestigio por una campaña fallida. Para Hekster la campaña breve del 180 fortaleció la posición de Cómodo y a partir de eso "though Commodus was secure, the empire was not" ${ }^{26}$ De hecho, la paz fijada por este gobernante duró hasta por lo menos el 250, por lo que su obra no fue equívoca.

\footnotetext{
${ }^{19}$ Grosso 1964.

${ }^{20}$ Hekster 2002, p. 2.

${ }^{21}$ López Fernández 2018, pp. 121-122.

${ }^{22}$ Alföldy 1971, pp. 84-109.

${ }^{23}$ Alföldy 1971,p. 84.

${ }^{24}$ Alföldy 1971,p. 104.

${ }^{25}$ Hekster 2002, p. 40.

${ }^{26}$ Hekster 2002, p. 40.
} 
El gran problema de Cómodo fue interno, al perder la nobleza senatorial privilegios en la administración imperial y al centralizar aun más el poder, esto lo distanció más y más del Senado, de donde proviene la crítica de la época. ${ }^{27}$ Por ello la invención de Cómodo como un personaje antagónico a Marco Aurelio surgió con las primeras conspiraciones senatoriales. En 182 el incremento del poder del emperador y el ascenso de cargos administrativos de tipo no senatorial, convirtieron a Cómodo en un enemigo directo de la nobilitas romana. Parte de la oposición del grupo senatorial se basó en diseñar una imagen negativa de este mandatario, la cual cobró sentido en siglos posteriores gracias a fuentes senatoriales como la Historia Augusta.

\section{LA GRAND STRATEGY Y CÓMODO}

Pero todos los análisis de la paz del 180 y de la campaña de aquel año de Cómodo se han centrado en comprender la decisión post quem; no se han basado en comprender los elementos que llevaron al joven emperador a tomar las decisiones, sino más bien en explicar la interpretación que las fuentes hicieron de esos procesos. Proponemos concentrarnos en los posibles elementos de orden estratégico que ocasionaron que Cómodo emprendiera ciertas acciones. Analizaremos la situación considerando el inacabado debate de la existencia o no de una Grand Strategy para el Imperio.

Las bases de esta discusión historiográfica llevan más de 40 años. ${ }^{28} \mathrm{El}$ concepto de Grand Strategy acuñado por Lidell Hart a mediados del siglo xx, entendido como la correlación de todos los mecanismos del Estado para lograr un objetivo militar a través de recursos económicos y humanos disponibles, ${ }^{29}$ ha sido apoyado o rechazado por muchos historiadores en su aplicabilidad al mundo antiguo. Un grupo de historiadores aceptó sin ambages el análisis propuesto por Luttwak sobre la aplicabilidad de la noción de Grand Strategy al estudio de la política exterior del Imperio romano. Otro grupo de historiadores niega la aplicabilidad del concepto basándose en que la estructura de control y acceso a la información era de tipo primitivo como para poder visualizar todos los elementos de manera interrelacionada y controlada. ${ }^{30}$

Nuestra idea es entrar en esa discusión a partir de las decisiones estratégicas del 180. Para ello tomaremos algunos elementos que la historiografía ha esgrimido en ambas posturas para aceptar o negar la proposición de las resoluciones de Cómodo respecto a la campaña contra los marcomanos o cuados. Consideraremos elementos de análisis derivados del artículo de

\footnotetext{
${ }^{27}$ Alföldy 1971, p. 85.

${ }^{28}$ Sáez 2017, pp. 1-25.

${ }^{29}$ Lidell Hart 1967, pp. 11 y 202.

${ }^{30}$ Wheeler 1993a, pp. 7-41, y 1993b, pp. 215-240.
} 
Fergus Millar, "Emperors, Frontiers and Foreign Relations, 31 B. C. to A. D. 378", 31 publicado como una reacción al punto de vista de Luttwak. Por otro lado, utilizaremos el modelo analítico de Koliopoulos y Platias en el que aplican conceptos de la Grand Strategy en el contexto del relato tucidideo de las guerras del Peloponeso como método para explicar los conflictos en el mundo antiguo. ${ }^{32}$ El debate en todo caso es más extenso y variado, pero lo circunscribiremos a algunos elementos particulares que nos interesa destacar en el análisis propuesto.

Ambas investigaciones buscaron comprender las múltiples interrogantes que conforman las redes conceptuales que dieron origen a la política exterior en el mundo clásico grecorromano. Para Millar, la estructura del Imperio romano sólo permitía que las tomas de decisiones fueran totalmente personalistas en un contexto de escasa cantidad y calidad de acceso a información geográfica y etnográfica. Para ello centró su análisis en los agentes de la decisión de la política exterior, en la responsabilidad y comunicación, en la dirección de los asuntos exteriores, en la concentración de la toma de decisiones y en el uso de la información disponible. Millar concluye que el bajo nivel informativo, la lentitud en los procesos de comunicación, la ausencia de un "staff" especializado en la guerra y asuntos exteriores, así como la concentración de la toma de decisiones en manos del emperador configuraron un sistema primitivo que se basó en decisiones limitadas y que llevaron inexorablemente a una sobrecarga de elementos en manos del gobernante. ${ }^{33}$

Para Luttwak, Koliopoulos y Platias es posible traducir al lenguaje moderno el funcionamiento estratégico del mundo clásico. ${ }^{34}$ En ese contexto de reflexión los aspectos que deberían considerarse son la diplomacia y las amenazas exteriores, la capacidad económica del Estado para sostener conflictos, la legitimidad de la que dispusieron los gobernantes en el nivel institucional y doméstico, así como los objetivos que propuso la política exterior. ${ }^{35}$ Para Luttwak esos objetivos en el siglo in se tradujeron en el desarrollo de fronteras científicas y de defensa preventiva, que precisamente con Cómodo inician una transición a la defensa en profundidad. ${ }^{36}$ Con todos

${ }^{31}$ Millar 1982, pp. 1-23.

${ }^{32}$ Koliopoulos-Platias 2010, pp. 1-2.

${ }^{33}$ Para la información geográfica, cf. Millar 1982, p. 2; sobre los agentes de decisión, pp. 4-7; en cuanto a comunicación y responsabilidad, pp. 7-11; para toma de decisiones, pp. 11-15; sobre uso de información, pp. 15-19, y acerca de decisiones limitadas y sobrecarga, pp. 20-23.

${ }^{34}$ Luttwak 1976. Para reseñas del uso de su terminología para el Imperio romano, cf. Cohen 1978, pp. 174-175; Wheeler 1993a, pp. 7-41; Hanson 1999, pp. 379-413; Valdés 2011, pp. 89104, y Koliopoulos-Platias 2010, pp. 1-2.

${ }^{35}$ Koliopoulos-Platias 2010, p. 19.

${ }^{36}$ Luttwak 1976, pp. 56-145. 
estos elementos es posible explorar cómo, dónde y con qué fuerzas los estados antiguos garantizaron su seguridad exterior.

Para comprender y explicar en su ámbito histórico las medidas implementadas por Cómodo en 180, analizaremos la situación tomando solamente tres criterios derivados de la discusión historiográfica enunciada: 1) los objetivos del Imperio romano y las amenazas externas e internas, 2) los agentes de decisión imperial y 3) los imperativos de orden económico.

\section{LOS OBJETIVOS DEL IMPERIO ROMANO, LAS AMENAZAS EXTERNAS E INTERNAS}

En época Antonina asiduamente se suele comparar a Trajano con sus "pacíficos" sucesores Adriano y Pío, o con el emperador filósofo Marco Aurelio, que pasó más años guerreando que dedicado al culto de la reflexión estoica. Esas comparaciones se derivaron de la historiografía romana con su carga moral ${ }^{37}$ y se acostumbró comparar emperadores con la finalidad de construir estereotipos consecuentes con las explicaciones políticas que se querían dar. En ese contexto la imagen de Cómodo como rector de los asuntos exteriores del Imperio también ha sido afectada. Marco Aurelio, el sabio, pero cuyo ejemplo está más cercano a Trajano, se opone al de un Cómodo que abandona la guerra para abrazar los placeres mundanos, tal como en 117 la imagen de Adriano se oponía a Trajano por retirarse de las conquistas orientales.

Al respecto podríamos preguntarnos si es que el Imperio romano tuvo objetivos sólidos en sus relaciones exteriores como lo sostiene Luttwak. Es difícil convencerse de que dicho Imperio analizara de una manera científica similar a la actual su situación militar. A nuestro juicio, el Imperio romano se guió más bien por valores y conceptos legitimadores de la actuación pública. En esa senda cabe destacar en el plano de la defensa imperial los valores que emergen con más fuerza en el siglo II: la securitas y la pax.

En este marco de entendimiento romano, la guerra y la paz eran parte de una misma realidad. Según Dión Crisóstomo, los monarcas debían estar preparados siempre para la guerra, por lo que en épocas de paz debían ejercitarse en el desarrollo de la misma. ${ }^{38}$ Tanto la paz como la guerra en el mundo romano no pueden verse simplemente como antónimos, de allí que el objetivo de la política fronteriza del Imperio romano no pueda ser reducida a la realización de ofensivas o de mantenerse a la defensiva.

La primera tarea que todo emperador romano tenía era mantener la pax romana, que como sostiene Woolf puede ser entendida en un sentido laxo

\footnotetext{
${ }^{37}$ La idea de que el periodo es de "buenos emperadores". Debate en Canto 2003, pp. 305-

${ }^{38}$ D.Chr., Real., 1, 22, ed. 1988.
} 347. 
y doméstico como un "state of order and security". ${ }^{39}$ Por eso Cómodo tuvo que acometer la reflexión de la prosecución de una guerra que por sus características podríamos definir como total contra los germanos y cuyas consecuencias se veían mediatizadas para garantizar el orden y la tranquilidad públicas al interior y exterior del Imperio romano.

La supuesta creación de las dos nuevas provincias de Marcomania y Sarmatia ha servido como evidencia para que los historiadores debatan sobre los verdaderos alcances de la campaña germánica, si es que Cómodo abandonaba una expedición exitosa o si, por el contrario, los exiguos recursos con los que contaba el Imperio romano hacían imposible consolidar la ocupación territorial. ${ }^{40}$

El joven gobernante habría interpretado - y de seguro también sus asesores - que la anexión de estos nuevos territorios en la ribera septentrional del Danubio no significaba la llegada de la paz, sino que generaría nuevas tribulaciones para el Imperio romano. Puede haber repercutido en este pensamiento lo acontecido en época de Trajano con la creación de las provincias de Dacia, Armenia, Mesopotamia y Asiria. ${ }^{41}$ Adriano tuvo que acometer un debate similar y optó por una retirada estratégica de Oriente y una reformulación de los límites de Dacia, dándole un carácter más uniforme y racional para la defensa. ${ }^{42}$ La idea de seguir en campaña contrastaba con la aparición de nuevos enemigos (los burios) y con el agotamiento general de las fuerzas del Imperio, sobre todo las demográficas y económicas. Firmar una paz favorable a Roma con los germanos en el Danubio no parecía ser una mala e irracional decisión estratégica.

Pero la seguridad exterior del Imperio romano no sólo presentaba inconvenientes derivados de la campaña danubiana. Como se demostraría años después, Britania también vivía una situación convulsa. Adriano había intentado frenar los problemas con la construcción del muro y el afianzamiento en general de la provincia insular. Antonino Pío, mediante sus legados, trató de avanzar al norte y construir un segundo muro para mantener el control de la provincia, pero la experiencia no había sido del todo positiva, ya que este segundo intento había sido abandonado entre 160 y 170 generándose un conflicto latente, paralelo a las guerras germánicas. ${ }^{43}$ Muchos de estos problemas estallaron en 184, una campaña de ese año permitió que Cómodo recibiera su sexta salutación imperial y el título de Britannicus Felix.

Situación similar se puede encontrar en las provincias de África del Norte donde los mauritanos incursionaban desde el 170, llegando a amenazar His-

\footnotetext{
${ }^{39}$ Woolf 2002, p. 176.

40 Alföldy 1971, p. 95.

${ }^{41}$ Mariqc 1959, pp. 261-262.

${ }^{42}$ Gudea 1979, pp. 63-87.

${ }^{43}$ SHA., Marc., 22, 2, ed. 1989.
} 
pania en tiempos de Marco Aurelio. Hallamos en la Mauritania Cesariense una inscripción del 185 en la que se menciona una reconstrucción de torres y muros para la seguridad de los habitantes de la provincia. ${ }^{44}$ Hay otras inscripciones en el Rin con el mismo sentido de reconstrucción de muros, torres y puertas, las que se entienden en el contexto de las guerras marcomanas. ${ }^{45}$

En el mismo tópico de la seguridad interna, a finales del principado de Marco Aurelio el aumento del bandidaje era un tema preocupante para las autoridades imperiales. Una inscripción del 182-185 de Intercisa, en Panonia Inferior, habla de la construcción de un burgus para vigilar el camino del borde del Danubio y controlar el paso de clandestinos latrunculorum. ${ }^{46}$ En África encontramos un modelo similar de control de movimientos con la construcción de un burgus Commodianum speculatorium. ${ }^{47} \mathrm{La}$ aparición de estos nuevos lugares y la aparición del concepto securitas en la epigrafía nos permite presuponer que se trataba de un tema de importancia crucial para la ideología y administración imperial.

De esta forma, al asumir Cómodo el poder en 180 los informes de la situación del Imperio romano no debían de haber sido del todo óptimos, la guerra en sí misma, los problemas en Britania, África y el bandidaje requerían atención inmediata. En el caso de la guerra en el Danubio, salvo por la interpretación de unos restos arqueológicos, así como lo señalado por Dión Casio y la Historia Augusta de que la rendición de los pueblos danubianos era prácticamente un hecho, no hay nada que nos induzca a pensar, y Cómodo debe haberlo visto de manera similar, que la guerra contra los bárbaros estaba concluyendo. La verdad es que la guerra marcománica estaba siendo de muy larga duración, el agotamiento de las fuerzas de Roma ya era notorio y crear dos nuevas provincias era una decisión que iba en contra de la conservación del Imperio.

44 ILS, 396, ed. 1892: Imp(erator) Caesar M(arcus) Aurel(ius) Comodo / Antoninus Aug(ustus) P(ius) Germanicus Sarmaticus Brittanicus / maximus securitati provincialium suorum consulens / turres novas instituit et veteres refecit oper(a) militum / [s]uorum curante / Cl(audio) Perpetuo proc(uratore) suo.

${ }^{45}$ CIL, III, 13439, 14370, ed. 1873. AE., 1983, 730.

${ }^{46}$ ILS, 395, ed. 1892= CIL, III, 3385, ed. 1873: per loca opportuna ad clandestinos latrunculorum transitus oppositis.

${ }^{47}$ CIL, VIII, 2495, ed. 1881: Imp(eratore) Caes(are) [M(arco)] Au[relio] / [[[C]ommo[d]o]] Antoni/no Pio Felice Aug(usto) [G]erm(anico) / Sarm(atico) Britannic[o] p(atre) p(atriae)/ trib(unicia) p[ot]e(state)XIII co(n)s(ule) V/burgum [[Commodi]]/[[anum]] s[p]eculato/rium inter duas vilas ad salutem comme/antium nova tutel[l] a c[o]nstitui iussit [Ti(berius)] / [Claudi]us [G]ordia[nus] / v(ir) [c(larissimus)] leg(atus) Aug(usti) pr(o) pr(aetore) / [cur]a agen[te. 


\section{Los AGENTES DE DECISIÓN IMPERIAL EN El DANUBio EN 180}

Los agentes de decisión según Fergus Millar correspondían a quienes participaron de una u otra forma en la toma de decisiones sobre las políticas exteriores del Imperio romano. Entre los actores clave de este proceso podemos encontrar al Senado, los amici y el consilium que asesoraba al emperador en múltiples materias. En el caso militar tendríamos que remitirnos a quienes iban en campaña con el emperador. ${ }^{48}$ De todos modos, debemos comprender que el Senado como institución a mediados del siglo II había perdido poder en la toma de decisiones: principalmente recibía informes de las campañas, como los de Lucio Vero y Avidio Casio, algunas embajadas, además votaba los honores y salutaciones honoríficas de los emperadores. ${ }^{49}$

Desde el inicio del Imperio algunos asesores directos del emperador, sobre todo sus amigos de la clase senatorial y ecuestre, asumieron mayor preponderancia en la toma de decisiones. De acuerdo con Millar este grupo estaba asociado a lo civil, por lo que no configuró un grupo experto en la materia, pero de todas formas intervenía en asuntos militares, según el historiador británico no existía un consejo general de guerra o una instancia similar. ${ }^{50}$ En campaña el emperador solía consultar a quienes tenía a su lado: gobernadores, amici, comites, legati, praefecti. Al tratarse de consejos consultivos, sus opiniones podían quedar en nada ya que la decisión final recaía en el emperador; precisamente Millar usa a Cómodo como un ejemplo de que el princeps podía tomar una decisión totalmente diferente a los consejos dados por sus asesores. ${ }^{51}$

Según Dión Casio, Marco Aurelio dejó a su hijo bajo la protección del Senado, lo que en términos de la campaña se podría entender como sus comites y amici que estaban con él en ese momento. No tenemos muchas pruebas de quiénes podrían haber estado durante el 180 en el cuartel general imperial, ${ }^{52}$ pero sería interesante develarlo. En las fuentes escritas, Herodiano pone en boca del cuñado de Cómodo, Tiberio Claudio Pompeyano, el liderazgo dentro de este grupo de amigos, familiares y asesores. Según Galimberti, ${ }^{53}$ además de Tiberio Claudio Pompeyano, es probable que se encontrara el suegro de Cómodo: Brutio Presente, con conexiones políticas y familiares con los Antoninos, nieto de Laberio Máximo, general de Trajano, tribuno militar en Siria en la III legión Gálica, alguien cuyo cursus honorum no era militar pero no obstante había sido designado para ser co-

\footnotetext{
${ }^{48}$ Crook 1975, pp. 2-4, 69-78.

${ }^{49}$ Millar 1992, p. 343.

${ }^{50}$ Millar 1982, p. 6.

${ }^{51}$ Millar 1982, p. 7.

${ }^{52}$ No hay claridad si se encontraba en Vindobona o Sirmio.

${ }^{53}$ Galimberti 2014, p. 63.
} 
mes Impp(eratorum) Ant[onini et Veri Augg(ustorum)] / expeditionis. ${ }^{54}$ Otro familiar que pudo encontrarse, también sin experiencia militar, era Marco Petronio Sura Mamertino, yerno de Marco Aurelio. Sin duda junto a ellos se encontraba Tarrutenio Paterno, prefecto del Pretorio, cuya maestría estaba ligada principalmente a la escritura militar y legal.

Junto con los anteriores posiblemente pudiera hallarse el amigo del emperador filósofo, Cneo Claudio Severo, comes en Atenas el 176, pero también de poca experiencia militar. Pertinax, estrella castrense en ascenso, había dejado el cargo de legado de las tres Dacias en 179, para ser destinado a Siria en el 180; quizá en su paso a su nueva destinación pudo haberse encontrado en algún minuto en el cuartel imperial, en su condición de protegido de Tiberio Claudio Pompeyano. Movimiento vinculado a este último fue el de Aufidio Victorino quien terminó su legación en Siria en 179, para ser designado en 180 praefectus urbi, un puesto clave en la protección de la ciudad en caso de un problema sucesorio.

Al parecer fue recurrente que Marco Aurelio colocara en puestos de confianza y beneficiara constantemente a sus familiares con cargos y dignidades, ${ }^{55}$ lo que explicaría la composición de este grupo de consejeros. Pareciera que en la composición de los consilia imperiales anteriores la amistad y el parentesco no eran un rasgo primordial, esto podría explicarse con una máxima del emperador filósofo: Aequius est, ut ego tot talium amicorum consilium sequar, quam ut tot tales amici meam unius voluntatem sequantur. ${ }^{56}$

En las fuentes hay tres generales de quienes poco sabemos. Se trata de Publio Salvio Juliano, quien se menciona como general de los ejércitos en Germania: tenía el puesto de legado de la Germania Inferior pero no hay más detalles de su cursus honorum. ${ }^{57}$ Las fuentes también se refieren a los hermanos Quintilios como generales de carrera, con habilidades militares y queridos por sus tropas. Se trata de los gobernadores de la Panonia Superior Sexto Quintilio Máximo y de la Panonia Inferior Sexto Quintilio Condiano, ambos dejaron sus puestos a finales de 179.58 Este último ascendió a cónsul, junto con el general Julio Vero, quien fue designado cónsul para 180,

${ }^{54}$ CIL, X, 408, ed. 1883: L(ucio) Fulvio C(ai) f(ilio) Pom(ptina) [Rustico C(aio)] / Bruttio Praesenti Min[---] / [Val]erio Maximo Pompeio L(ucio) [---] / Valenti Cornelio Proculo [---] / Aquilio Veientoni co(n)s(uli) II pr[aef(ecto) urbi patri] / [C]r[i]spinae Aug(ustae) socero Imp(eratoris) [Commodi Aug(usti) sodali] / Hadrianali sodali Antonin[iano Veriano] / Marciano comiti Impp(eratorum) Ant[onini et Veri Augg(ustorum)] / expeditionis Sarmaticae p[raetori cand(idato) quaes]/tori Aug(usti) tr(ibuno) mil(itum) leg(ionis) III Gallic[ae adlect(o) inter patric(ios)] / ab Imp(eratore) divo Antonino Aug(usto) Pio.

${ }^{55}$ SHA., Marc., 16, 1, ed. 1989.

56 SHA., Marc., 22, 4, ed. 1922, trad. de Picón y Cascón: "Es más justo que yo siga el consejo de tantos y tan eximios amigos que tantos y tan eximios amigos sigan mis deseos".

${ }^{57}$ SHA., Comm., 3, 1, ed. 1989. D.C., 72, 5, ed. 1927.

${ }^{58} P I R^{2}$, Q.22. Q.24, 1933. 
pero no pudo ocupar el cargo debido a que falleció a causa de la peste o de la guerra. Los Quintilios fueron asesinados por Cómodo, pues según Dión Casio sus competencias militares eran un riesgo para el emperador. ${ }^{59}$

Entre 179 y 180 se produjo una serie de cambios en el equipo de gobernadores y legados legionarios que podrían haber constituido un problema en la realización de una ofensiva militar. En Panonia la salida de los Quintilios dio paso, al menos en la Panonia Inferior, al gobierno de Lucio Septimio Flaco (179-183), del cual no tenemos novedades sobre su cursus honorum. De la Panonia Superior no hay noticias acerca de quién sucedió a Quintilio Máximo. En Dacia, la salida de Pertinax a finales de 179 e inicios del 180 dio paso a Gayo Vetio Sabiniano, quizá el único gobernador del momento con reputada experiencia militar, dilectus de la III itálica, legado de la XIV Gemina y de la Panonia Superior hacia el 175, guarneció Roma en el momento de la rebelión de Casio, por lo que fue beneficiado con el consulado en 176, siendo luego enviado a terminar el problema del bandidaje en Dalmacia en 177, para finalmente asumir la provincia de Dacia, el bastión en la defensa del limes danubiano. ${ }^{60}$ Es probable que en la Germania Inferior se nombrara gobernador a Didio Juliano en 178, otra personalidad militar en ascenso, mientras en la Germania Superior, el gobernador Publio Cornelio Anulino, quien antes había derrotado a los mauritanos y había tenido el mando de Retia, terminaba su mandato en $180 .{ }^{61}$

En el caso de las legiones, en 179 Valerio Maximiano pasaba de la I legión Adiutrix a la II Adiutrix en territorio marcománico: después sería nombrado comandante de varias legiones, lo que sumado al hecho de la adlectio por Marco Aurelio nos permite suponer que se trataba de un general con mucha experiencia militar destinado en particular a dirigir fuerzas durante la nueva campaña. ${ }^{62}$ De acuerdo con Dión Casio es probable que se encontraran en una situación similar Clodio Albino y Pescenio Nigro, futuros pretendientes de la púrpura imperial a la muerte de Pertinax. ${ }^{63}$ En cuanto a Clodio Albino, se dice que jugó un papel importante para el apoyo a Marco Aurelio en las legiones de Oriente al momento de la rebelión de Avidio Casio en 175. La Historia Augusta señala que dispersó a pueblos que habitaban más allá del Rin: in qua fusis gentibus Transrenanis celebre nomen suum et apud Romanos et apud barbaros fecit. ${ }^{64}$

${ }^{59}$ D.C., 73, 5, 3, ed. 1927.

${ }^{60} P I^{1}, \mathrm{~V}, 339$, ed. 1897.

${ }^{61} P I R^{2}, \mathrm{C}, 1323$, ed. 1933.

${ }^{62} A E ., 1956,124$.

${ }^{63}$ D.C., $72,8,1$, ed. 1927.

${ }^{64}$ SHA., Clod., 6, 3, ed. 1922, trad. de Picón y Cascón: "donde hizo célebre su nombre no sólo entre los romanos, sino también entre los bárbaros, porque puso en fuga a los pueblos que habitaban más allá del Rin”. 
Éstos pudieron ser algunos de los agentes con los que Cómodo tuvo que buscar consejo para tomar una decisión respecto a la prosecución de la secunda expeditio Germanica. De acuerdo con los nombres podemos al menos encontrar dos grupos. El primero de ellos correspondería a quienes estaban en el cuartel imperial con los emperadores, un grupo en el que hallamos al prefecto del pretorio, los amici más cercanos y, sobre todo, emparentados de manera directa con los Augustos. En ese grupo se destaca una personalidad militar, Tiberio Claudio Pompeyano, quien según Herodiano representa a este clan al aconsejar a Cómodo seguir con la campaña hasta llegar al Océano, ya que las condiciones estaban dadas para ello. Compartimos la idea de Alföldy, Hekster y Fraschetti quienes creen que el discurso del experimentado general fue una invención didáctica narrativa de Herodiano para contraponerla a la imagen del emperador joven en vías de corrupción con la de un general reputado y desapegado del poder. ${ }^{65}$ Para Baldini el consilium convocado por Marco Aurelio en el Danubio funcionaba como un Senado restringido que participaba en la toma de decisiones políticas y militares, en el que muchas veces la experiencia militar no fue todo lo importante que debía ser en una campaña bélica. ${ }^{66}$ Para Millar la discusión desde el punto de vista de los agentes que ayudaban al emperador en la toma de decisiones representa la inutilidad de estas instancias de consejo, ya que "This is a cardinal instance of the essential weakness of the position of the amici or comites" ${ }^{67}$

Es un hecho que en 180 hubo una renovación de los liderazgos en el Danubio, cuestión no menor. En el Agrícola de Tácito se desprende que un oficial al mando de tropas o de una provincia requería un tiempo prudente para noscere provinciam, nosci exercitui ${ }^{68}$ Esto es relevante, puesto que gobernadores y legados eran quienes entregaban la información táctica a Cómodo. ¿Por qué cambiar el personal al mando en una época en que supuestamente se iba a desarrollar una nueva campaña militar contra los cuados, marcomanos y los iazygos? Las respuestas son variadas, ya que no encontramos otros indicios en las fuentes. Lo primero es que Marco Aurelio, siempre considerado con las tradiciones del Senado, decidió respetar la lógica de la duración de los cargos de legados provinciales, de manera que aquellos nombrados en 175-176, quienes prepararon la campaña del 178 , se encontraban por concluir su mandato a finales del 179 e inicios del 180 .

Una segunda cuestión que podría aducirse es el impacto de las bajas en el cuerpo de senadores, producto de la peste y la guerra. Sabemos que Macrino

\footnotetext{
${ }^{65}$ Alföldy 1971, pp. 86-87. Hekster 2002, p. 6. Fraschetti 2014, p. 261.

${ }^{66}$ Baldini 1978, p. 666.

${ }^{67}$ Millar 1982, p. 5.

68 Tac., Agr., 5, 1, ed. 1914, trad. de Requejo: "conocer la provincia y que el ejército lo conociera".
} 
Vindex murió en 176; Basaeo Rufo, reconocido por obtener victorias contra germanos y sármatas en campaña, falleció entre el 179-180; Vitrasio Polión, con experiencia militar en el bajo Danubio, cónsul en 176, premiado en campaña y pariente de los padres de Cómodo, murió también antes del 180; por último, Cneo Julio Vero falleció en el 179 sin poder ocupar el consulado designado que tenía para 180. De modo que, en el momento crucial del 180, tanto Marco Aurelio como su hijo tenían como asesores a gobernadores nuevos, que estaban conociendo el oficio, excepto Julio Hospes en Dacia. ${ }^{69}$ Para recuperar las bajas, muchos oficiales de clase ecuestre fueron elevados mediante la adlectio a la categoría senatorial por Marco Aurelio, con méritos nada desdeñables. El caso más relevante que conocemos es el de Marco Valerio Maximiano, procedente de África.

Esto último nos lleva a la tercera cuestión: la primera campaña de Cómodo en el 180 fue una operación para cubrir de gloria militar al recién ascendido emperador. Sin duda ése debe haber sido un consejo de los asesores más inmediatos tomando en consideración el patrón de otros ascensos imperiales. Desde el 170 Roma venía ganando batallas y Marco Aurelio obtuvo salutaciones de las victorias sobre los germanos. Del total de 10 salutaciones que el emperador filósofo recibió, tres fueron derivadas de la campaña oriental de Vero $(161,163,165$ y 166), las restantes de las guerras septentrionales en 168, 171, 174, 175, 177 y 179. Cómodo había recibido todas las salutaciones desde 175 como co-emperador, la primera en 176, la segunda en 177 gracias a las victorias de los Quintilios en Panonia y la tercera en 179 por Tarrutenio Paterno, todas conseguidas principalmente por otros generales. Se hacía urgente validar al emperador frente al Senado y al ejército como líder militar en solitario; de hecho, es lo que se desprende del primer discurso público a las tropas como emperador en solitario. ${ }^{70}$ Debe haber sido una opinión generalizada que el muchacho de 15 años llevado a campaña por su padre no había adquirido mucha experiencia militar. Cómodo lidió con esto: realizó campañas en Dacia - región que tenía al gobernador más experimentado-, se aseguró la cuarta salutación, volvió a Roma legitimado militarmente y con una paz duradera garantizando con ello la seguridad de la frontera danubiana.

Cabe destacar un último aspecto político. En las Meditaciones el clima de pesadumbre es evidente respecto a los conflictos bélicos, ${ }^{71}$ Dión Casio puso en boca del emperador filósofo que éste se encontraba cansado por la

${ }^{69}$ Vindex: PIR ${ }^{2}$, M.22, ed. 1933, Rufo: ILS, 1326, ed. 1892. Vero: $P I R^{2}$, I, 618, ed. 1933. Hospes: PIR ${ }^{1}, \mathrm{~V}, 339$, ed. 1897.

${ }^{70}$ Hdn., 1, 5, 1-3, ed. 1985. Comentario histórico, texto y traducción del discurso en Galimberti 2014, pp. 62-67.

${ }^{71}$ Marc., Med., 4, 32, 10, 9, ed. 1916. Cf. Fraschetti 2014, p. 250, sobre el pesimismo de Marco Aurelio y sus efectos en la toma de decisiones. 
guerra, ${ }^{72}$ y Amiano repite una anécdota donde Marco Aurelio deja entrever su desgano con los enemigos del septentrión: Marcomanni, o Quadi, o Sarmatae, tandem alios vobis inertiores inveni.$^{73}$ A ello se suma que existía un círculo opuesto a la guerra. Este círculo podría haber sido relativamente cercano a la revuelta de Casio, y pudo haber seguido existiendo, no directamente opuesto a Marco Aurelio, pero sí como grupo de presión, considerando que los hijos y partidarios de Avidio Casio fueron perdonados por el emperador filósofo y posteriormente asesinados por orden de Cómodo, lo que podría explicar el nombramiento de Aufidio Victorino, de absoluta confianza para Marco Aurelio y su hijo, como prefecto de la ciudad en 179$180 .^{74}$

Para el 180 existía un clima de agotamiento generalizado. Pensemos en que Cómodo, nacido en 161, había pasado toda su vida en torno a las noticias de guerra, peste y hambruna. Como se lo cuestiona Fraschetti sería lícito reflexionar hasta qué punto el emperador filósofo había sido efectivamente un buen padre como para que Cómodo pudiera transformarse en el mejor de los hijos y continuara con el eventual mandato de seguir con el conflicto ${ }^{75}$ De todos modos, creemos que en el contexto político ceremonial romano la presencia de Cómodo en Roma era fundamental.

Por ello, desde un punto de vista político, no es para nada incorrecta e irracional la decisión de firmar la paz con los germanos con condiciones ventajosas para Roma: entre ellas se contaban el control del comercio en las fronteras, una franja desmilitarizada, el internamiento de grupos germanos como mano de obra en las provincias devastadas, elementos que podrían favorecer una romanización de estos pueblos y su integración a largo plazo en el ámbito provincial. ${ }^{76}$ Sin duda, más allá de la narrativa moral adversa de Herodiano, de Dión Casio y la Historia Augusta, el círculo senatorial que se encontraba con Cómodo en 180 apoyó la decisión de firmar las paces. Un suceso posterior que podría arrojar una luz de comprensión tendría que ver con las consecuencias del intento de asesinato de Cómodo en 182, orquestado por Lucila, esposa de Pompeyano. A pesar de la falta de su mujer, el experimentado general pudo retirarse en calma y no fue hostigado durante todo el principado de Cómodo, lo mismo pasó con otros personajes, excepto con Paterno, implicado directamente en el complot.

72 D.C., 71, 23, 3, ed. 1927.

73 Amm. Marc., 22, 5, 5, ed. 1935-1940, trad. de Harto Trujillo: “ ¡Oh marcomanos!, ¡Oh cuados!, ¡ Oh sármatas, al fin he encontrado a pueblos más turbulentos que vosotros!”.

${ }^{74}$ SHA., Marc., 26, 10-13, ed. 1989. Fraschetti 2014, p. 214.

${ }^{75}$ Fraschetti 2014, p. 228.

${ }^{76}$ Hekster 2002, pp. 48-51. 


\section{LOS IMPERATIVOS DE ORDEN ECONÓMICO}

Desde el punto de vista estratégico vale la pena examinar los asuntos económicos y cómo éstos pudieron influir para firmar la paz en el 180, sobre todo porque las guerras de Marco Aurelio en términos de duración fueron más largas que las de Trajano: la Historia Augusta menciona que fue de tal magnitud que no se recordaba guerra similar, salvo la II Guerra Púnica. ${ }^{77}$ Sin duda es posible colocar el impacto general de la Peste Negra en la primera preocupación de tipo económico. Se estima que la peste acabó con un porcentaje entre el 13 y 15\% de la población total del Imperio romano, esto es, unos cuatro millones de habitantes ${ }^{78} \mathrm{El}$ impacto demográfico de la peste se encuentra presente en casi todas las fuentes literarias; en muchos acuerdos firmados por Marco Aurelio en el marco del conflicto se estipulaba que los pueblos vencidos debían entregar guerreros: 5000 sármatas fueron a Britania y otros tantos se establecieron en Dacia y el Danubio, a esas estipulaciones se añadían las relativas a la devolución de los prisioneros. No es extraño que dichas situaciones fueran materia de discusión legal, como se aprecia en el Digesto, sobre la condición jurídica de quienes regresaban de la guerra y el postliminio. $^{79}$

La reducción demográfica afectó la estabilidad del Imperio. El mismo Marco Aurelio podría haber muerto de peste. Los efectos en la economía fueron brutales porque se redujo la mano de obra para la producción agrícola y artesanal; el desarrollo de las guerras en el norte no ayudaba a disminuir la presión sobre el sistema productivo, al contrario, ${ }^{80}$ Marco Aurelio subastó bienes del Estado y personales para recaudar dinero. ${ }^{81}$ Por ello es factible creer que, al llegar al poder, Cómodo recibió un erario público bastante presionado a causa de la guerra sostenida contra los germanos.

El tema del erario público y la demografía se cruza con el del reclutamiento militar. La Historia Augusta menciona que en los tiempos aciagos del enfrentamiento contra los germanos Marco Aurelio reclutó gladiadores, esclavos y ladrones con la finalidad de conformar unidades militares. ${ }^{82} \mathrm{En}$ el caso de las unidades auxiliares el número de diplomas que conocemos entre el 175 y el 192 es sumamente escaso por lo que, o bien se alargaron los años de servicio debido a las bajas en combate, o por efecto de la peste. A ello hay que añadir la creación de las legiones II y III Itálica, creadas por Marco Aurelio en 165 y desplegadas en Retia y Norico.

\footnotetext{
77 SHA., Marc., 17, 2, ed. 1989.

${ }^{78}$ Littman, M.-R. Littman 1973, pp. 252-255.

${ }^{79}$ Birley 1993, p. 189. Dig., 49, 15, ed. 1889.

${ }^{80}$ Fraschetti 2014, pp. 233-247.

${ }^{81}$ SHA., Marc., 17, 4, ed. 1989.

${ }^{82}$ SHA., Marc., 21, 7, ed. 1989.
} 
A esto debemos sumar los costes de tener un ejército de ocupación operando al norte del Danubio. El avituallamiento de las legiones y auxiliares tanto en alimentos como en materiales de construcción no debió de ser menor, sobre todo si atendemos a la cantidad de obras de reconstrucción que ya mencionamos. La presión demográfica y económica pudo llegar a niveles intolerables, muchas veces las tropas se mostraron reacias con la negación de donativos por parte de Marco Aurelio, el agotamiento bélico debió hacer mella en muchos que pudieron terminar desertando y dedicándose al bandidaje, esto creaba un clima de inseguridad interna.

Según Baldini, el desgaste de la guerra tuvo dos consecuencias: en las clases populares orientales estalló la revuelta de los boukoloi y en la clase senatorial oriental se produjo la revuelta de Avidio Casio. ${ }^{83}$ En ambos casos las consecuencias financieras para el Imperio fueron importantes, pues se trataba de regiones que vinculaban el comercio mediterráneo con el área pérsica y además por el abastecimiento de grano egipcio. Marco Aurelio, si creemos a la Historia Augusta, aparte de realizar algunas mejoras en el procedimiento de distribución, sufrió varios momentos de hambruna ${ }^{84}$ y ayudó también a ciudades, lo que no se tradujo en un inmediato aumento de la carga fiscal, sino al contrario: tal como su abuelo adoptivo Marco Aurelio decidió perdonar una serie de deudas públicas. Junto con ello la creación de unas supuestas nuevas provincias añadiría una carga aun mayor al erario romano y nuevos desajustes en el sistema monetario. Por todo lo anterior, el tesoro romano con sus ingresos regulares tuvo que sufragar una guerra de casi 20 años continuos ${ }^{85}$ cuyos beneficios no se compararon con los de Trajano en su campaña dácica que mejoraron la condición de las finanzas imperiales.

En este contexto de decadencia económica derivada de las guerras y del corte de las rutas comerciales, sobre todo en el curso del Danubio, no nos debe extrañar que en Dacia encontremos inscripciones que declaran a Cómodo como restitutor comerciorum ${ }^{86}$ por parte de libertos imperiales esto nos muestra, junto con las medidas militares tomadas contra las bandas de ladrones y la reconstrucción de caminos, los beneficios económicos de la paz firmada por el joven emperador en 180 .

\section{DISCUSIÓN FINAL Y CONCLUSIONES}

Basándonos en el hecho de que el recién ascendido emperador tomó una decisión estratégica, donde "estratégico" quiere decir que se correlaciona-

\footnotetext{
${ }^{83}$ Baldini 1978, p. 636.

${ }^{84}$ SHA., Marc., 11, 1-5; 12, 13; 23, 3, 4, ed. 1989.

${ }^{85}$ Baldini 1978, p. 664.

${ }^{86} A E ., 1988,977$.
} 
ron diferentes aspectos de la política exterior imperial, la cuestión central está en determinar si Cómodo dispuso de información, militar y económica, que le permitiera comprender los problemas en una dimensión estratégicaglobal.

El debate del acceso a la información de los emperadores es un tema recurrente y no menor. Como se ha mencionado, para Millar los emperadores romanos no recibían toda la información requerida, ésta les llegaba fraccionada, por lo que sus decisiones carecían de elementos fundamentales de juicio político y militar. De hecho, el historiador británico considera que el gran tema es la escasez de información geopolítica para la política militar. Para el siglo II, contamos con evidencia, aunque fragmentaria, que al menos nos permite presuponer que los emperadores tenían acceso a información de primera mano.

Contamos con una serie de reportes importantes de unidades militares. En Vindolanda hay una serie de reportes, el más interesante es el de Julio Verecundo de la I cohorte de tungrios a finales del siglo I e inicios del II en el que se informan destinaciones y ausencias para destacar el estado total de la fuerza de la cohorte ${ }^{87}$ según Apiano, ésa era una costumbre frecuente en el siglo II. ${ }^{88}$ Dichos reportes debieron concatenarse en la estructura jerárquica y del mando militar. Disponemos incluso de documentos detallados sobre los reclutas de la III cohorte de itureos acantonada en Egipto donde se mencionan los rasgos físicos de los soldados que se iban a reclutar. ${ }^{89} \mathrm{Al}$ tratarse de documentos oficiales, su emisión debe haber sido constante; por lo tanto, un general tenía cómo saber el estado de su ejército y las condiciones de combate de sus unidades.

En el Epistolario de Plinio el Joven hay varios ejemplos de la cantidad de información militar que podía generar una provincia pacífica y sin tropas: reportes de espías y embajadores despachados rápidamente a Roma para entrevistarse con Trajano, otros datos concernientes a los preparativos de abastecimiento con miras a la campaña oriental. ${ }^{90}$ Gracias a las epístolas de Frontón, escritas en el centro de la dinastía Antonina, sabemos de cartas enviadas al Senado en forma de reporte que permiten la declaración del triumphus, litteras militis vincetur, ${ }^{91}$ el maestro se siente orgulloso de la carta que su pupilo Vero ha hecho llegar al Senado y de la eloquentia de la misma rem militarem magistra eloquentia usus est..$^{92}$ En tales cartas encontramos las laureatas litteras traídas del frente por un tribuno de Avidio

\footnotetext{
${ }^{87}$ TV., II, 122-177, en particular n ${ }^{\circ}$ 154, ed. 1994. Bowman-Thomas 1991, pp. 62-73.

${ }^{88}$ App., BC., 5, 43, ed. 1985.

${ }^{89}$ P.Oxy., VII, 1022, ed. 1910.

${ }^{90}$ Plin., Ep.Xr., 19, 20, 21, 22, 27, 28, 29, 30, 63, 64, 67, 74, 87, ed. 2007.

${ }^{91}$ Fronto, Ep., 181, 1, ed. 1919.

${ }^{92}$ Fronto, Ep., 181, 18, ed. 1919.
} 
Casio donde notifica el gran éxito de la campaña oriental. ${ }^{93}$ A ello sumamos que Lucio informó personalmente al Senado de sus acciones en la campaña oriental, al modo de Trajano, como afirma Dión Casio, e igual que Adriano al dirigirse al Senado para informar la situación de las tropas en el contexto de la revuelta judaica (132-135). ${ }^{94}$ No estamos ante información aislada, sino, más bien, ha sobrevivido fragmentada. El Imperio romano con toda su tradición y burocracia generaba muchos datos.

Pero, ¿Cómodo tuvo acceso a esta información? En nuestra opinión sí, tanto en la forma en que los miembros del consilium y amigos de Marco Aurelio se la pudieron entregar, como la información oficial derivada de los reportes oficiales de índole militar que se discutían en las diferentes reuniones de la campaña del Danubio. Cómodo no careció de información política y militar para tomar su decisión. La decisión de firmar la paz con los germanos fue argumentada y racionalizada para los cánones del pensamiento militar romano. Cabe destacar la complejidad de un sistema imperial como el romano que, sin los beneficios tecnológicos de la modernidad, fue capaz de adquirir información que dispuesta para el uso del emperador y su "staff" más cercano permitía tomar determinaciones tácticas y estratégicas. En cuanto a los resultados de todos los vaivenes militares en el bajo Danubio y desde un punto de vista estratégico la región no generó grandes problemas por lo menos hasta mediados del siglo III, por eso la determinación de Cómodo mostró ser correcta.

Queda pendiente una última reflexión en torno a si la existencia de este cúmulo de informaciones militares significó que Cómodo las utilizara como gobernante. La respuesta es parcial, desde una mirada deductiva podría plantearse como premisa general que, durante el siglo II, en particular durante los Antoninos, esto fue un hecho, pues los emperadores sí usaron todo el material disponible para tomar decisiones políticas y militares. El joven emperador sólo continuó utilizando un modelo administrativo, de manera que la praxis de gobierno se mantuvo inalterable y el mandatario se limitó a seguir unos patrones ya conocidos. Desde un punto de vista inductivo, la evidencia de informes militares no nos remite directamente a la época de Cómodo, por lo que, si se atiende la tesis de Millar, es posible creer que el personalismo haya cambiado toda la praxis de gestión militar del Imperio romano debido a la singularidad de Cómodo.

En este artículo tratamos de demostrar que hacia el siglo II el Imperio romano había consolidado una serie de prácticas militares y de gestión política que reflejaban unas formas de pensar estratégicamente la situación imperial. Bajo esta perspectiva comprendemos la documentación militar analizada en

\footnotetext{
${ }^{93}$ Fronto, Ep., 193, 1, ed. 1992.

${ }^{94}$ D.C., $69,14,3$, ed. 1927.
} 
páginas anteriores. Este conjunto de ideas conformó un sistema plenamente interrelacionado de elementos, en los cuales podríamos encontrar la visión del emperador acerca de las relaciones exteriores, la distribución de tropas, la concepción en torno a la guerra y la religión, entre otros aspectos.

Cómodo fue parte de ese sistema y también de esa manera de pensar y concebir las relaciones exteriores del Imperio romano. Su experiencia como César entre el 175 y 180, su participación directa e indirecta en las decisiones de la guerra germánica, el asesoramiento que le brindaron los viri militaris y su propia práctica de gobierno en solitario son elementos que creemos permiten sostener este punto de vista.

La idea de Cómodo de tomar una determinación pensada es un contrapunto para la visión general que se tiene del emperador. Esta situación equívoca proviene de un defecto historiográfico más que de la posibilidad de reconstruir lo acontecido. La Historia Augusta, por ejemplo, presenta a un Marco Aurelio émulo de Trajano en cuanto al desarrollo de sus campañas, esto se opone a un Cómodo que imita a Adriano retirándose de las provincias orientales. Los círculos senatoriales tradicionalistas beneficiados por el poder otorgado por Marco Aurelio al Senado - poder trastocado por el proyecto de centralización imperial de Cómodo - crearon una imagen en la que los defectos del joven emperador se exacerbaron al grado de no reconocer en él atisbo de racionalidad.

Nos queda otra cuestión relevante. ¿Cuánta influencia pudieron tener el consilium y los agentes políticos en la decisión de Cómodo? Esto es difícil de explicar. La buena o mala herencia de este dignatario estuvo mediatizada porque el grupo de senadores que siguieron a Marco Aurelio en campaña no eran todos de orden militar, sino familiares y gente cercana; en ese sentido el consilium no fue un "staff" profesional de guerra como propusiera Millar. A nuestro juicio no se puede ser categórico porque se trató de una coyuntura particular, esto requiere un análisis de otras campañas de época Antonina para determinar el funcionamiento de los asesores directos de los emperadores. Hay una cuestión que escapa del marco temporal de la campaña danubiana, se refiere a si la composición de los comités de Trajano y Adriano tuvieron una lógica similar en las diferentes campañas y expediciones que emprendieron. A simple vista pareciera que Marco Aurelio sobreexplotó la dimensión familiar y amistosa en demérito de la profesional, pero eso es algo que, insistimos, otros estudios deberán indagar.

A primera vista pareciera que el consilium patrocinó el retorno de Cómodo a Roma, dando con ello su venia al acuerdo con los germanos. Muchos miembros que aparecen en esta época tuvieron después carreras destacadas, otros cayeron en desgracia por confabular, mientras, según Herodiano, el más encarnizado opositor a la retirada, Claudio Pompeyano, vivió en un apacible retiro político a pesar de una conjura de su esposa, hermana del 
joven emperador. El relato de Herodiano basado en el choque de dos fuerzas contrapuestas, el denuedo juvenil de Cómodo frente a la experimentada voz militar de Pompeyano, representante de los amici, parece más bien un recurso retórico y no una realidad del momento.

Una última cuestión interesante en el análisis de los hechos tiene que ver con el cambio en los liderazgos políticos y militares del Imperio romano, las carreras de quienes se encontraban en la región danubiana no han podido reconstruirse por completo, al contrario de época anteriores, lo que quizá nos habla del ascenso de personas de orígenes más humildes, pero también de la necesidad de adaptación del Imperio romano a los nuevos tiempos, en los cuales personajes como Níger, Clodio Albino y Septimio Severo serían actores fundamentales. Esto también nos lleva a una conclusión que permite explicar cambios posteriores: en la campaña de Cómodo en el 180 los legados legionarios, la mayoría de ellos ascendidos mediante la adlectio al orden senatorial, tenían más experiencia militar que los gobernadores y asesores directos del emperador, presagiando el cambio militar del siglo III.

Como conclusiones, se puede señalar que, analizadas en conjunto las decisiones de Cómodo en el plano político, militar y económico, éstas no son diferentes a las medidas tomadas por otros emperadores, como Adriano. La virtud del trabajo desarrollado en este artículo radica en comprender las tres dimensiones de una manera conjunta, lo que nos da un sentido más amplio de la acción política de Cómodo, y en particular de la decisión tomada en el 180 sobre concluir la campaña danubiana.

Hemos utilizado un hecho militar puntual, la retirada de Cómodo del Danubio, para analizar los elementos que un emperador pudo tener a la mano para tomar decisiones. Creemos en ese sentido en una superación de las ideas de Millar, quien considera que el emperador y su estudio se reducen a sus acciones. Las formas de pensar, o cómo pudo haber pensado el joven emperador, nos ayudan a desentrañar las prácticas de las instituciones imperiales. El conjunto de cuestiones a las que tuvo que prestar atención un emperador, Cómodo en este caso, nos permiten presuponer la existencia de un sistema complejo: desde la obtención de la información militar necesaria sea de índole política, militar, etnográfica o geográfica, hasta su procesamiento de acuerdo con ciertas pautas mentales.

Esta complejidad del sistema imperial permite señalar que el emperador Cómodo no se comportó de manera disoluta en su primera decisión, por lo que el motivo del retorno a Roma para disfrutar de lo mundano pareciera pueril, ya que el poner fin a la guerra con los germanos, que llevaba más de 10 años agotando los recursos del Imperio, se mostraba como una decisión absoluta y totalmente racional. En este caso vale la pena recalcar que el sentido racional tiene relación con la cosmovisión que los romanos dieron 
a sus formas de pensamiento político y militar, en el fondo, a una ideología del Imperio romano, la pax romana.

De este modo se han aportado dos nuevas visiones sobre el Imperio romano. La primera, relativa a la visión biográfica de Cómodo, no sólo como un emperador perdido en fiestas y alejado del gobierno, sino como un emperador que se rigió por ciertos códigos de gobierno aprendidos por toda la nobilitas imperial de la cual él era miembro. En segundo lugar, resulta interesante la discusión sobre las formas prácticas y mentales en las que los emperadores romanos pudieron tomar sus decisiones, pero también lo que operacional y racionalmente se comprendió en la propia época como tal. Respecto a lo último, en futuros estudios, cabría seguir explorando la idea del concepto de pensamiento estratégico romano con la finalidad de superar el ya añoso debate inconcluso de la Grand Strategy romana.

\section{BIBLIOGRAFÍA}

\section{Fuentes antiguas}

Amiano Marcelino, Historia, ed. María Luisa Harto Trujillo, Madrid, Akal (Akal Clásica), 2002.

Ammianus Marcellinus, Res Gestae, transl. John C. Rolfe, Cambridge, Harvard University Press (Loeb Classical Library), 1935-1940.

Apiano, Historia Romana: Guerras Civiles. Libro V, trad. Antonio Sancho Royo, Madrid, Gredos (Biblioteca Clásica), 1985.

Aurelio Víctor, Libro de los Césares, trad. Ema Falque, Madrid, Gredos (Biblioteca Clásica), 2008.

Corpus Inscriptionum Latinarum, vol. III, ed. Theodor Mommsen, Berlin, Academiae Litterarum Borusicae, 1873.

Corpus Inscriptionum Latinarum, vol. VIII, ed. Theodor Mommsen, Berlin, Academiae Litterarum Borusicae, 1881.

Corpus Inscriptionum Latinarum, vol. X, ed. Theodor Mommsen, Berlin, Academiae Litterarum Borusicae, 1883.

Dio Cassius, Roman History, transl. Earnest Cary, Cambridge, Harvard University Press (Loeb Classical Library), 1927.

Dión de Prusa, De la Realeza I, trad. Gaspar Morocho Gayo, Madrid, Gredos (Biblioteca Clásica), 1988.

Eutrope, Abrégé de l'histoire romaine, trad. Nicolas-Auguste Dubois, Paris, Garnier Frères, 1865.

Eutropio, Breviario, trad. Ema Falque, Madrid, Gredos (Biblioteca Clásica), 2008.

Frontón, Epistolario, trad. Ángela Palacios Martín, Madrid, Gredos (Biblioteca Clásica), 1992.

Herodiano, Historia del Imperio romano después de Marco Aurelio, trad. Juan José Torres Esbarranch, Madrid, Gredos (Biblioteca Clásica), 1985. 
Historia Augusta, ed. Vicente Picón y Antonio Cascón, Madrid, Akal (Akal Clásica), 1989.

Inscriptiones Latinae Selectae, ed. Herman Dessau, Berlin, Academiae Litterarum Borusicae, 1892.

Justiniano, Digesto, trad. Ildefonso García del Corral, Barcelona, Jaime Molina Editor, 1889.

L'Année épigraphique, Paris, Presses Universitaires de France, 1956.

L’Année épigraphique, Paris, Presses Universitaires de France, 1983.

L’Année épigraphique, Paris, Presses Universitaires de France, 1988.

Marcus Aurelius, Marcus Aurelius, ed. and transl. Charles Reginald Haines, Cambridge, Harvard University Press (Loeb Classical Library), 1916.

Marcus Cornelius Fronto, The corresponde of Marcus Cornelius Fronto, ed. and transl. Charles Reginald Haines, Harvard University Press (Loeb Classical Library), 1919.

Plinio el Joven, Epistolario (Libros I-X) y Panegírico del emperador Trajano, trad. José Carlos Martín, Madrid, Cátedra (Letras Universales), 2007.

Prosopographia Imperii Romani Saec. I. II. III, vol. 1, second edition, Berlin, Academiae Litterarum Borusicae, 1897.

Prosopographia Imperii Romani Saec. I. II. III, vol. 2, second edition, Berlin, Academiae Litterarum Borusicae, 1933.

Scriptores Historia Augustae, ed. and transl. David Magie, Cambridge, Harvard University Press (Loeb Clasical Library), 1922.

Tácito, Agrícola, Germania, Diálogo de los oradores, intr., trad. y notas José María Requejo, Madrid, Gredos (Biblioteca Clásica), 1981.

Tacitus, Dialogus, Agricola, Germania, ed. William Peterson, Cambridge, Harvard University Press (Loeb Clasical Library), 1914.

The Oxyrhynchus Papyri, vol. VII, ed. and transl. Bernard P. Grenfell and Arthur S. Hunt, London, Egypt Exploration Fund, 1910.

Vindolanda Tablets Online, http://vindolanda.csad.ox.ac.uk/ (10/11/2019).

\section{Fuentes modernas}

Alföldy, Geza, "Der Friedensschluss des Kaisers Commodus mit den Germanen", Historia: Zeitschrift für Alte Geschichte, 20, 1971, pp. 84-109.

BALDINI, Antonio, "Le rivolta bucolica e l'usurpazione di Avidio Cassio (Aspetti del principato di Marco Aurelio)", Latomus, 37/3, 1978, pp. 634-678.

Birley, Anthony, Marcus Aurelius: A Biography, London, Barnes \& Noble Books, 1993.

Bowman, Alan and David Thomas, "A Military Strength Report from Vindolanda", Journal of Roman Studies, 81, 1991, pp. 62-73.

Canto, Alicia, "La dinastía Ulpio-Aelia (98-192 d.C.): Ni tan 'Buenos', ni tan 'Adoptivos', ni tan 'Antoninos' ”, Gerión, 21/1, 2003, pp. 305-347.

Cohen, Eliot, "Reviewed Work: The Grand Strategy of the Roman Empire: From the First Century A. D. to the Third. by Edward Luttwak", Political Science Quarterly, 93/1, 1978, pp. 174-175. 
Crook, John, Consilium Principis: Imperial Councils and Counsellors from Augustus to Diocletian, New York, Arno Press, 1975.

EsPINOSA, Urbano, "El reinado de Cómodo: subjetividad y objetividad en la antigua historiografía”, Gerión, 2, 1984, pp. 113-149.

Fraschetti, Augusto, Marco Aurelio: La miseria de la filosofía, Madrid, Marcial Pons, 2014.

Galimberti, Alessandro, Erodiano e Commodo: Traduzione e commento storico al primo libro della Storia dell'Impero dopo Marco, Göttingen, Vandenhoeck \& Ruprecht, 2014.

Garzetti, Albino, From Tiberius to the Antonines, London, Methuen, 1974.

GibBon, Edward, The Decline and Fall of the Roman Empire, London, Joseph Ogle Robinson, 1830.

Grosso, Fulvio, La lotta politica al tempo di Commodo, Torino, Memorie dell'Accademia delle Scienze di Torino, 1964.

GudeA, Nicolae, “The Defensive System of Roman Dacia”, Britannia, 10, 1979, pp. 63-87.

Hanson, Victor David, "The Status of Ancient Military History", Journal Military History, 63, 1999, pp. 379-413.

HeKster, Olivier, Commodus: An Emperor at the Crossroads, Leiden, Brill, 2002.

Koliopoulos, Constantinos and Athanasios Platias, Thucydides on Strategy, London, C. Hurst \& Co. Publishers, 2010.

Lidell Hart, Basil, The Strategy of Indirect Approach, London, Faber and Faber, 1967.

Littman, Maxwell and Robert Littman, "Galen and the Antonine Plague", The American Journal of Philology, 94/3, 1973, pp. 252-255.

López Fernández, José A., Campañas dacias y marcomanas: la dinastía Ulpio-Aelia en las fronteras septentrionales de Roma (101-180 D.C.), Granada, HRM Ediciones, 2018.

LutTwak, Edward, The Grand Strategy of the Roman Empire: From the First Century A.D. to the Third, Baltimore, Johns Hopkins University Press, 1976.

MacLynn, Frank, Marco Aurelio: guerrero, filósofo, emperador, Madrid, Esfera de los Libros, 2011.

MARICQ, André, “La Province d'Assyrie créée par Trajan”, Syria, 36, 1959, pp. 254276.

Millar, Fergus, "Emperors, Frontiers and Foreign Relations, 31 B. C. to A. D. 378", Britannia, 13, 1982, pp. 1-23.

Millar, Fergus, The Emperor in the Roman World, London, Duckworth, 1992.

SÁEZ, Andrés, "Estrategia e Imperio romano: un balance historiográfico a 40 años de la publicación de The Grand Strategy of the Roman Empire", Revista Historias del Orbis Terrarum: Anejos de Estudios Clásicos, Medievales y Renacentistas, 14, 2017, pp. 1-25.

VAldÉs, Pau, "El debate sobre la Grand Strategy romana", Revista de Historiografía, 14, 2011, pp. 89-104.

WheELER, Everitt, "Methodological Limits and the Mirage of Roman Strategy: Part I", Journal of Military History, 57, 1993a, pp. 7-41. 
WheELer, Everitt, "Methodological Limits and the Mirage of Roman Strategy: Part II", Journal of Military History, 57, 1993b, pp. 215-240.

Woolf, Greg, "Roman Peace", in John Rich and Graham Shipley (eds.), War and Society in the Roman World, London, Routledge, 2002.

$$
* * *
$$

Andrés SÁez Geofrroy es doctor en Historia Antigua por el programa de Societat i Cultura de la Universitat de Barcelona. Se desempeña como académico de la Universidad de La Frontera, Temuco, Chile; es profesor de Historia en el Departamento de Ciencias Sociales. Es miembro del CEIPAC de la Universitat de Barcelona y de GAHIA, e investigador responsable del proyecto FONDECYT N 11180219 "La Pax Antonina: ideología militar, política exterior y gran estrategia del Imperio romano en el siglo de los Antoninos". 